\title{
The Bexley Hospital population nine years on
}

\author{
S. J. Kelly
}

\begin{abstract}
A survey was undertaken at the beginning of 1995 of all the patients in the Bexley Hospiltal. Demographic information was compared with the findings obtained from a previous survey conducted in 1986. Results indicated that during the 9-year interval, changes had occurred in the characteristics of the population. Most markedly, the group was younger than that originally studied, and the total proportion of legally detained patients had increased. If such trends are representative of the country at large, adequate planning must be made to cater for an ever-evolving patient group.
\end{abstract}

Community-based facilities have been increasingly introduced into many districts across the country which cater for patients in long-stay psychiatric hospitals. Bexley Hospital, which is scheduled for closure before the end of the century, provides such an example of an institution included within a reprovision programme. Despite its plans for closure, Bexley Hospital is still actively used to provide acute. continuing care, intensive care and elderly services. The past 10 years have seen the closure of three wards which previously catered for patients from the catchment areas of Lewisham and North Southwark. Two wards provided continuing care and rehabilitation, whereas the other provided beds for elderly patients requiring continuing care. At the time of writing. Bexley Hospital provides six wards for patients from the Lewisham and North Southwark catchment areas (three provide services for rehabilitation and continuing care; two for elderly services; and one for acute care).

To establish the needs of patients to be discharged, many districts have surveyed their hospital populations. In a study of the long-stay populations of five hospitals, Clifford et al (1991) found that the populations were predominantly elderly, with a mean age of 64.5 years. The average length of stay was 24.5 years, and half had been in hospital for more than 20 years. The authors concluded that "The study confirms the view that psychiatric hospitals in the UK now contain a predominantly elderly and severely disabled population, many of whom have been in hospital for very long periods of time."
In a study of the long-stay populations of the Friern and Claybury Hospitals, O'Driscoll et al (1993) also found that for both populations, approximately half had a length of stay of 20 years or more. The mean number of previous psychiatric admissions for the Friern and Claybury populations were two and one respectively; $21 \%$ of the population at the Friern and $29 \%$ at the Claybury Hospital were experiencing their first admission. Of the Friern population, $11 \%$ had had 10 or more previous admissions to a psychiatric hospital; whereas for the Claybury group, the figure was $8 \%$.

The current paper reports a survey, conducted between October 1994 and January 1995, of the Lewisham and North Southwark population resident in Bexley Hospital. This population was previously surveyed in 1986 (Clifford \& Szyndler, 1986). Consequently, changes in the composition of this population between 1986 and the present can be established.

\section{The study}

Surveys were completed for all patients in the Bexley Hospital, from the catchment areas of Lewisham and North Southwark, with the exception of those with a primary diagnosis of senile dementia. The total population studied consisted of 72 patients. Demographic information was collected for all patients from their case notes.

\section{Findings \\ Gender}

Of the 72 patients surveyed, $45(62.5 \%)$ were male and $27(37.5 \%)$ female. In comparison, Clifford \& Szyndler (1986) found that of 111 patients, $48(43 \%)$ were male and $63(57 \%)$ female. Such data indicate that between 1986 and 1995 there was a decrease in the overall number of Lewisham and North Southwark patients in Bexley Hospital, which can be attributed to the closure of wards and placement of patients into the community. There was an increase in the percentage of males within the population. This difference may well be related to 
the changing profile of the population. The 1986 population was considerably older than that studied in 1995 (see below), and consequently, there were likely to be more women given the greater the age of the population then.

\section{Age}

In 1986, the mean age of the population was 62.9 years, compared with $\mathbf{5 2 . 6}$ years in the current survey. In the 1986 population, $62 \%$ of the population were over the age of 60 . In the present survey, only 39\% were over 60 .

\section{Ethnic origin}

In the 1986 survey, $89 / 111$ patients $(80 \%)$ were White, compared with $56 / 72$ patients $(75 \%)$ in 1995. In 1986, $21 / 111$ patients (19\%) were Black compared with $14 / 72$ patients (19\%) in 1995. In $19861 / 111$ patients (1\%) was Asian compared with $2 / 72$ patients $(3 \%)$ in 1995 . Therefore, no major differences exist in the ethnic make-up of patients between the two periods of study.

\section{Length of study}

The average length of stay for the current population is 9.6 years, ranging from 1 year to 50 years. This compares with an average length of stay of 16.8 years in the 1986 population (Table 1).

In the 1986 population, 50 patients $(45 \%)$ had been in hospital for more than 10 years compared with 24 patients (33.3\%) in the 1995 population. In the 1986 population, 24 patients (22\%) had been in hospital for 5-10 years, as compared with nine patients $(12.5 \%)$ in the current population. In the 1986 population, 37 patients (33.3\%) had been in hospital for less than five years compared with 39 patients $(54.2 \%)$ in 1995.

Therefore, there has been a considerable decrease in lengths of stay for the Lewisham and North Southwark patients between 1986 and 1995; the average length of stay has almost halved.

Table 1. The distribution of lengths of stay for Lewisham and North Southwark patients in Bexley Hospital in 1986 and 1995

\begin{tabular}{llc}
\hline & \multicolumn{2}{l}{ Number of patients (\%) } \\
\cline { 2 - 3 } Length of stay (years) & 1986 & 1995 \\
\hline $1-5$ & $37(33 \%)$ & $40(54 \%)$ \\
$6-10$ & $24(22 \%)$ & $9(13 \%)$ \\
$11-20$ & $16(14 \%)$ & $13(19 \%)$ \\
$21-30$ & $10(9 \%)$ & $5(7 \%)$ \\
$31-40$ & $6(5 \%)$ & $2(3 \%)$ \\
$41-50$ & $7(6 \%)$ & $3(4 \%)$ \\
$51-60$ & $11(10 \%)$ & 0 \\
\hline
\end{tabular}

\section{Psychiatric admissions}

The mean number of psychiatric admissions for the 1995 population was seven. Only five patients $(6.9 \%)$ were experiencing their first admission, while 20 patients $(27.8 \%)$ had 10 or more previous admissions.

\section{Legal status}

The total number of legally detained patients in Bexley Hospital for 1986 and 1995 was 3/111 $(2.7 \%)$ and $25 / 72(34.7 \%)$ respectively, indicating that there has been a considerable increase in the number of legally detained patients. In fact. the percentage of legally detained patients in 1995 was almost 13 times that in 1986.

\section{Comment}

The results from this study indicate that between 1986 and 1995, there have been changes in the characteristics of the Lewisham and North Southwark population resident at the Bexley Hospital, from a predominantly elderly, female. informal population with a long length of stay, to a predominantly middle-aged, male, legally detained population with a greatly reduced length of stay. The conclusions of Clifford et al (1991) and O'Driscoll et al (1993) that psychiatric hospitals in the UK now contain a predominantly elderly population with long lengths of stay appears, therefore, to be confounded.

The considerable decrease in the proportion of patients spending 10 years or more in Bexley Hospital between 1986 and 1995 can be explained in terms of the increase in younger patients and steady attrition of the elderly institutionalised population. Perhaps also Bexley Hospital has been effective in preventing people with severe mental health problems becoming long-stay patients.

The only disturbing factor in the changing population between 1986 and 1995 is the number of legally detained patients. One explanation is that since the current population consists of younger patients than in 1986, more behavioural disturbances might be present. Also, perhaps, the majority of patients from the 1986 survey who had informal status are no longer resident in Bexley Hospital and their places have been taken up in part by legally detained patients.

The data for previous psychiatric admissions were not available for the 1986 population. However, for comparison's sake, the figures obtained for 1995, were compared with those obtained by O'Driscoll et al (1993), whose population was not dissimilar to the 1986 Bexley population. For the Friern and Claybury Hospitals, the mean number of psychiatric admissions were two and one respectively: $21 \%$ 
of the Friern Hospital population and $29 \%$ of the Claybury population were experiencing their first admission. Furthermore, $11 \%$ of the patients from the Friern and $8 \%$ from the Claybury Hospital had experienced 10 or more admissions. Such figures bear no similarity to those obtained for the current Lewisham and North Southwark population. From these data, therefore, it is possible to suggest that a large proportion of the current Bexley population are being admitted to and discharged from hospital before they have the opportunity of becoming long-stay patients.

It would appear that both younger and more elderly patients are being discharged from Bexley Hospital, but a greater proportion of younger people are being admitted in their place. Such data highlight the need for more emphasis to be placed upon the needs and requirements of younger people with severe mental health problems. Planning for community care must also take the needs of future generations of people with severe mental health problems into consideration, since new facilities should meet the needs of these individuals, as well as of current patient groups.

\section{Acknowledgements}

The author thanks the staff and patients at the Bexley Hospital for their kind cooperation during the completion of this survey: particularly Dr Susan Cope. Dr Hilary Foster, Isobel Morris and the Lewisham Resettlement Team (Bexley Hospital), and Dr Peter Simpson (University of Surrey) for their most helpful advice.

\section{References}

CuFrord. P. \& SzYndLeR, J. (1986) Bexley Patients' Needs Survey. London: National Unit for Psychiatric Research and Development.

-. Charman, A., WebB, Y., et al (1991) Planning for community care. Long-stay populations of hospitals scheduled for rundown or closure. British Journal of Psychiatry. 168, 190-196.

O'Driscoll. C., WILLS, W., LEFF, J., et al (1993) The TAPS Project 10: The long-stay populations of Friern and Claybury Hospitals. The baseline survey. British Journal of Psychiatry. 162 (suppl. 19), 30-35.

Sarah J. Kelly, Department of Psychology, University of Surrey, Guildford, Surrey GU2 5XH

\title{
Psychological Trauma - A Developmental Approach
}

\author{
Edited by Dora Black, Martin Newman, Jean Harris Hendriks and Gillian Mezey
}

This is the first UK textbook on psychological trauma and contains contributions by many of the country's leading authorities on responses to traumatic events. It is edited by four clinicians with extensive experience on this subject.

The book discusses normal and abnormal responses to stress, disasters, war and civil conflict, and interpersonal violence, diagnosis, interventions and treatments, and legal aspects. There is reference throughout to the research findings, and discussion of future research needs. Each chapter contains a comprehensive bibliography for those who wish to read further. Published January 1997, price £30.00, 424pp. ISBN 0902241982

Gaskell is the imprint of the Royal College of Psychiatrists. Gaskell books are available from good bookshops and from the Publications Department, Royal College of Psychiatrists, 17 Belgrave Square, London SW1X 8PG (Tel. +44(0)171 235 2351, extension 146). The latest information on College publications is available on the INTERNET at: http://www.demon.co.uk/rcpsych/

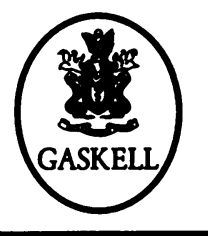

